\title{
NORBERT ELIAS, PODER E COTIDIANO
}

\author{
ADEMIR GEBARA \\ PVNS CAPES/UFGD / Brasil \\ am gebara@yahoo.com.br
}

RICARDO DE F. LUCENA

DFE/CE/UFPB / Brasil

ricoluce@hotmail.com

\section{Resumo}

O conceito de poder é central na obra de Norbert Elias, seu argumento básico centra-se na existência de diferentes fontes de poder, o poder é político, econômico, do conhecimento, simbólico, militar e também se expressa de variadas formas. Nesse sentido, sendo o poder central nas relações sociais, uma análise sociológica deve prestar atenção às mudanças que se produzem com e na distribuição de poder, fornecendo assim elementos mais palpáveis para a análise das interdependências e das configurações nas estruturas sociais.

Palavras-chave: Poder; Norbert Elias; distribuição de poder.

\section{Resumen}

\section{Norbert Elias, poder y cotidiano}

El concepto de poder es central en los libros de Norbert Elias. Su argumento básico centrase en la existencia de distintas fuentes de poder, el poder es político, económico, del conocimiento, simbólico, militar y también se expresa de variadas formas. En ese sentido, siendo el poder central en las relaciones sociales, un análisis sociológico debe estar atento a los cambios que se producen con y en la distribución de poder, forneciendo así elementos más palpables para el análisis de las interdependencias y de las configuraciones en las estructuras sociales.

Palabras-clave: Poder; Norbert Elias; distribución de poder.

\section{Abstract}

\section{Norbert Elias, power and daily life}

The concept of power is the central idea in Norbert Elias' book. Its basic argument focuses on the existence of different sources of power. The power is political, economical, of the knowledge, symbolical, military and also expresses itself in different ways. In this sense, with power being central to the social relations, a sociological analysis must be attentive to the changes that derive through and from the distribution of power, providing, therefore, more concrete elements for the analysis of the interdependences and configurations in the social structures.

Key words: Power; Norbert Elias; distribution of power. 
O conceito de poder em Norbert Elias está presente em praticamente todos os seus trabalhos, é categoria relevante com tratamento original. O poder é fruto de relações e, portanto, não é um fato posto e situado que pode ser isolado como uma coisa qualquer, mas algo relacional, inerente às interdependências que se estabelecem na prática social. O poder, diria Elias, tem haver com a existência de grupos ou indivíduos que:

Podem reter ou monopolizar aquilo que outros necessitam, como por exemplo, comida, amor, segurança, conhecimento, etc. Portanto, quanto maior as necessidades desses últimos, maior é a proporção de poder que detêm os primeiros (Elias, 1994: 53).

Nossa argumentação na discussão proposta será formulada com foco em três trabalhos do autor. O primeiro é a entrevista concedida por Elias a Peter Lucas e publicada com o título "CONOCIMIENTO Y PODER"; outro é o seu já famoso "Introdução à Sociologia"; e, por último, a obra "Os estabelecidos e os outsiders", escrita em parceria com J. Scotson.

É necessário primeiramente ter em conta que, para Elias, os debates sociológicos e políticos sobre o poder estão deformados, porque as discussões não estão centradas nos equilíbrios e graus de poder, ou seja, nos aspectos que tem a ver com as relações sociais. Como já dissemos, entende-se o poder como se fosse algo inerente à uma determinada instituição, uma coisa que se põe na bolsa, por exemplo, e não, como já frisamos, como algo relacional.

É preciso considerar que o argumento básico elaborado por Norbert Elias é que há diferentes fontes de poder, que ele é político, econômico, do conhecimento, etc., também se expressando de variadas formas, sendo o monopólio desses diferentes núcleos o que permite ao Estado se manter com um potencial elevado de poder. Portanto, não é à toa que a teoria eliasiana de processos civilizadores se fundamenta na ideia do monopólio de poder pelo Estado, inicialmente pela centralização do exercício da força e da cobrança de impostos - o poder militar e o poder econômico. Hoje, entretanto, Elias considera que o monopólio desses fatores depende do monopólio do conhecimento, como elemento que marca a emergência de grupos de classes subalternas através das lutas pelo direito à educação, por exemplo. Fato que demonstra, na análise de um período relativamente longo, a busca por um equilíbrio de poder que põe em movimento as sociedades humanas.

Entretanto, o sentido do processo de monopolização que entende apenas o poder de decisão nas mãos de um número cada vez menor de indivíduos, perde a noção de um processo em relação com

\footnotetext{
1 Esse texto é parte do volume cujo título também é "Conocimiento y poder", organizado e apresentado por Julia Varela. É composto por mais três texto escritos por Norbert Elias e o quarto texto é a entrevista que utilizamos aqui.
} 
a longa duração. Para Elias, não significa dizer que um número cada vez menor de pessoas se torna 'livre' e mais e mais pessoas se tornam 'não-livre'. Mas,

E o movimento é considerado como um todo, podemos reconhecer sem dificuldade que - pelo menos em sociedades altamente diferenciadas - em certo estágio do processo a dependência passa por uma mudança qualitativa peculiar. Quanto mais pessoas são tornadas dependentes pelo mecanismo monopolista, maior se torna o poder do dependente, não apenas individual mas também coletivamente, em relação a um ou mais monopólios (Elias, 1993: 100).

Continuando nessa linha de raciocínio, podemos destacar que a interdependência entre as classes sociais e os indivíduos dá margem a uma maior divisão de funções, bem como à criação de instituições mais sólidas e, cedo ou tarde, 'força' o poder monopolista a uma relação de dependência funcional, ante grupos com menor coeficiente de poder.

Será que poderíamos pensar que a busca desse equilíbrio de poder, para Elias, se configura como motor de todas as relações humanas? Em "Introdução à sociologia" isso aparece justamente quando trata dos "modelos de jogo" (pág. 87 - 112) para pensar as relações sociais. Assim, afirma Elias, que "o equilíbrio de poder não se encontra unicamente na grande arena das relações entre os Estados, onde é freqüentemente espetacular, atraindo grande atenção. Constitui um elemento integral de todas as relações humanas." (1980: 80).

Vale a pena ampliar esse caminho de análise, apontando o "modelo de jogos" como um modelo metodológico para perceber que, "utilizando a imagem de participantes de um jogo como metáfora das pessoas que formam as sociedades, é mais fácil repensar as idéias estáticas que se associam a maior parte dos conceitos usados nesse contexto" (Elias, 1980: 100) e, particularmente, o conceito de Poder.

Para Elias, o campo de estudos da sociologia - "as configurações de seres humanos interdependentes" -, não se pode explicar se estudarmos os seres humanos isoladamente. E é ao considerar essas relações que surge a necessidade de superar a ideia de poder que permeia a análise sociológica, na qual as conotações ofensivas, que consequentemente acompanham o conceito de poder, podem impedir a distinção entre os dados factuais - a que o conceito se refere - e a avaliação que se faz desses dados.

É necessário, portanto, discorrer um pouco mais sobre o modelo de jogos elaborado por Norbert Elias, tratando desde as competições primárias até as relações mais complexas dos modelos de processos de interpretação com normas.

Nas relações com modelo de competição sem regras, o exemplo é o de dois grupos, A e B, que se encontram numa luta prolongada pela sobrevivência. Dois grupos rivais, mas também dependentes um do outro, entre outras coisas porque os movimentos de um grupo determinam os 
movimentos do grupo rival, mantendo assim um contato constante. Os rivais desempenham uma função recíproca e a função recíproca que desempenham "baseia-se na coerção que exercem mutuamente devido a sua interdependência." (Elias, 1980: 84). A competição primária apresenta-se como um caso fronteiriço, onde um grupo busca privar o outro de suas oportunidades e, quiçá, de sua vida. As batalhas entre grupos rivais no controle do tráfico de drogas, nas entranhas das grandes cidades brasileiras, parecem um bom espaço para o entendimento desse modelo de competição.

Já nos "modelos de processos de interpenetração com normas", Elias busca discutir a mudança na teia de relações humanas e a na distribuição de poder. Daí decorrem diferentes possibilidades: desde o jogo de duas pessoas, em que $\mathrm{A}$ tem uma força muito superior a $\mathrm{B}$, até o "modelo de jogo a dois níveis tipo democrático crescentemente simplificado", onde a força dos jogadores - observemos os termos no plural - "de nível mais baixo vai crescendo, lentamente mas de modo nítido, relativamente à força dos jogadores de nível mais alto.” (Elias, 1980: 96). Passando ainda pelos "jogos de muitas pessoa a um só nível”; "jogos multipessoais a vários níveis”; "modelos de jogos de dois níveis: tipo oligárquico"; e "modelos de jogos a dois níveis: tipo democrático crescentemente simplificado”. Dessa emergência nas oportunidades de poder, decorrem consequências que ninguém planejou, e que, por isso mesmo, devem interessar ao estudo sociológico, considerando que há, ou derivam dela, interdependências humanas não intencionais na base de todas as interações intencionais.

Portanto, o modelo de jogos nos da uma ideia do caráter de integração que as sociedades representam. Constituem uma tentativa de superação da herança de interpretação das relações e dos jogos de poderes como cadeias unilineares de causa e efeito, tendo como fim ou como perspectiva um equilíbrio de poder mais homogêneo, fruto de uma maior participação nas oportunidades de poder.

Considerando que o termo "equilíbrio de poder" não é necessariamente sinônimo de igualdade de poder, Elias aponta que, tanto nas relações bipolares como, por exemplo, a de pai e filho, ou de senhor e escravo, e nas relações multipolares ou multipessoais, sejam "grandes ou pequenas as diferenças de poder, o equilíbrio de poder está sempre presente onde quer que haja uma interdependência funcional entre pessoas." (Elias, 1980: 81). Sendo assim, o poder é, sem sombra de dúvidas, e como fruto dessa interdependência, um atributo das relações. Na proporção da função que desempenha uma pessoa em relação à outra, ou um grupo em relação a outro, está a base em que se constrói o "equilíbrio de poder". Pois, indivíduos ou grupos destituídos de qualquer tipo de interdependência funcional, também se ignoram ou se desprezam mutuamente. Como se vê também, a ideia de função desempenha um papel relevante para entendermos a questão do poder e, como já frisamos, ao falar de funções nos referimos a interdependências que "constrangem as pessoas com maior ou menor amplitude". 
Foi o sentido de um poder inter-relacional, que permitiu Elias observar como variam as relações que se estabelecem entre grupos ou entre indivíduos, e como variam as influências mútuas entre os grupos sociais em cada momento histórico e em amplos períodos de tempo (1994a: 30). Foi esse sentido da análise que o permitiu entender o papel inter-relacional do Rei e sua corte, na análise que fez da sociedade francesa em "A sociedade de corte”. Depois, ver a formação do povo alemão e a ascendência de Hitler, em "Os Alemães”, ou o papel do simples indivíduo na teia reticular que forma com os demais, em "A sociedade dos indivíduos". Portanto, o que Elias chama a atenção, nas suas proposições sobre o poder, é o fato de os debates a respeito do tema normalmente não estarem centrados nos equilíbrios, nem nos graus de poder, ou por outra, nos aspectos das relações sociais.

Os aspectos do poder nas relações sociais mereceram um destaque especial na análise que $\mathrm{N}$. Elias e J. Scotson realizaram no bairro operário de Wiston Parva, mostrando, entre vários e interessantes elementos, que nem todas as formas de opressão social assumem a forma de relações de classe. No estudo em questão, no lugar de relações de classe, a relação entre estabelecidos e recémchegados é privilegiada no sentido de capturar melhor a realidade das relações de poder no cotidiano das pessoas, além das interdependências que se estabelecem no interior destas configurações. É conveniente atentar para o conceito de comunidade em Elias: trata-se de um grupo de vizinhos vivendo em uma localidade, ligados por interdependências funcionais mais próximas do que as interdependências de mesmo tipo de outros grupos dentro do campo social mais amplo ao qual a comunidade pertence ${ }^{2}$.

Em Wiston Parva, encontramos três diferentes agrupamentos. Um de classe média (zona 1), que foi uma área acrescida posteriormente ao empreendimento inicial, datado de 1880 e iniciado com a zona 2. Esta área, também denominada de Aldeia, foi habitada por uma classe trabalhadora mais numerosa, antiga e com laços familiares muito estreitos, implicando por isso mesmo uma maior participação associativa e comunitária, com um alto nível de organização no campo político. A zona 3, ou o Loteamento existente posteriormente aos anos 1940, tornou-se por inúmeras razões um bairro de migrantes. As relações entre a classe operária estabelecida na Aldeia e a classe operária migrante do Loteamento têm grande significação neste trabalho de Elias. Como se vê, trata-se de analisar processos de identificação a partir da relação entre grupos, o que constitui dificuldade não desprezível, tendo em vista a existência de unidades estatais plenamente consolidadas, como neste caso da própria Inglaterra.

Esta dificuldade deve-se, também, ao fato de que a referência identificadora está em processo de construção, tanto interior quanto exteriormente ao grupo focado, a par da existência de identidades mais abrangentes implicando a cidade, a região e a nação. A identidade nós está sendo construída por

2 Para maiores detalhes ver: ELISA, Norbert. Towards a theory of communities. In: BELL, C.; NEWBY, H. (eds) (1974). The Sociology of Community. London: Frank Cass. 
eles, de maneira a História de um grupo está sendo construída também por outro grupo. A questão é saber até que ponto o grupo nós tem poder para intervir neste processo, definindo a natureza de seu próprio pertencimento.

No estudo de caso proposto, não havia diferenças de nacionalidade, ascendência étnica, cor, raça, ou mesmo diferença significativa de moradia e renda entre os residentes das duas áreas. Tampouco havia diferença de nível educacional ou classe social. A diferença essencial estava no fato de um grupo viver na área a duas ou três gerações, enquanto o outro grupo residente caracterizava-se como recém-chegado.

Aqui temos um problema conceitual que não deve ser subestimado. Não se trata de abordar a questão pela lógica da exclusão, pois, a existência desta lógica implica já uma realidade inclusiva, em outras palavras, quando excluímos o outro, estamos reconhecendo sua existência, ainda que sejamos incapazes de identificá-lo claramente. Nesta relação de poder, o afloramento de tensões é permanente, provavelmente porque aceitar-se como eles implica em posição secundária no acesso às fontes de poder. Pensar conjuntamente o eu, o nós e o eles constitui o grande desafio sociológico, especialmente por termos aqui uma relação entre grupos com diferenciais de poder acentuados.

As configurações, por sua natureza múltipla e interdependente, acabam por constituir um poder coercitivo sobre os indivíduos que as constituem. É justamente essa questão que enraíza parte substantiva da elucidação do funcionamento dos mecanismos de poder no cotidiano, e, no caso de Wiston Parwa, a fofoca é um integrante privilegiado deste processo.

Norbert Elias ${ }^{3}$ oferece uma inovadora possibilidade para analisar as relações de poder entre grupos estabelecidos, em relação a grupos de fora, afirmando que, não obstante às variações na natureza das fontes de poder entre esses grupos, é possível identificar características comuns e constantes. Por isso mesmo estas "regularidades" generalizáveis poderiam aplicar-se a todas as outras análises das relações entre configurações (grupos).

Em linhas gerais, pode-se afirmar que o processo de estigmatização, manipulado pelas elites mais poderosas em relação aos seus grupos 'outsiders' - independentemente de diferenças culturais -, apresenta as seguintes características: ${ }^{4}$

1) As distinções de status entre os grupos estão enraizados em uma balança de poder desigual entre eles. Por exemplo, o grupo estabelecido possui relações familiares (casamentos e parentescos cruzados) e redes de comunicação formais e informais (clubes sociais locais, centros irradiadores e

\footnotetext{
${ }^{3}$ ELIAS, Norbert; SCOTSON Johan L. (2000). Os Estabelecidos e os Outsiders: Sociologia das relações de poder a partir de uma pequena comunidade. Trad. Vera Ribeiro. Rio de Janeiro: Zahar Editor. (Trabalho Original publicado em 1994).

${ }^{4}$ VAN KRIEKEN, Robert (1998). Norbert Elias. Coleção Key Sociogists. London/New York: Routledge. Ver especialmente o capítulo "Process Sociology Extended” (p. 135 -163).
} 
organizadores de fofocas). Esse primeiro grupo mantém um status superior em relação ao segundo grupo outsider, cujos membros têm como função certo "respeito" pelo grupo estabelecido. 5

2) Os diferenciais de poder entre os grupos geram uma relação dinâmica entre carisma e estigma. "O grupo estabelecido tende a atribuir ao conjunto do grupo outsider as características "ruins" de sua porção "pior" - de sua minoria anômica. Em contraste, a auto-imagem do grupo estabelecido tende a se modelar em seu setor exemplar, mais "anômico" ou normativo - na minoria de seus melhores membros." (2000, p.22 - 23).

Um exemplo significativo se verifica na relação entre os chamados portadores de necessidades especiais e o grupo composto por acadêmicos ${ }^{6}$, quando propõem a identificação do outro grupo multifacetado, denominado deficientes, ou x, ou y, ou z. É clara uma relação interdependente entre estes grupos, ainda que os acadêmicos detenham as melhores oportunidades de monopólio do poder nesta configuração, a balança de poder é movimentada no interior destas relações interdependentes. "A peça central dessa figuração é um equilíbrio instável de poder, com as tensões que lhe são inerentes. Essa é também a pré-condição decisiva de qualquer estigmatização eficaz de um grupo outsider por um grupo estabelecido" (Elias, 2000: 23). Há, portanto, uma complementaridade nós-eles, na relação entre os formuladores das práticas, quer sejam médicas, quer sejam pedagógicas. E os destinatários dessas práticas, $x, y$ ou z, todos portadores, quer sejam de necessidades, quer sejam de deficiências, a escolha será sempre um produto da manifestação do poder do grupo estabelecido.

3) É difícil para os membros de um grupo outsider resistir ao processo de internalização das características negativas que lhe são atribuídas pelo grupo estabelecido.

$\mathrm{O}$ argumento que vem sendo desenvolvido coloca no centro das relações de interdependência (entre o grupo acadêmico e o grupo com denominação imprecisa) não a questão de uma possível inferioridade humana - inferioridade que, de resto, explicita-se nas diferentes denominações propostas, deficientes ou portadores de necessidades especiais -, mas, sobretudo, é o diferencial de acesso às fontes de poder, o fator distintivo da identidade destes grupos: "quando o diferencial de poder é grande e a submissão inelutável, vivenciam afetivamente sua inferioridade de poder como um sinal de inferioridade bumana".

Certamente, a especificação das diferentes características físicas (cegos, paraplégicos), acobertadas pela uniformidade dos termos genéricos (deficientes ou portadores), nos permitirá observar

\footnotetext{
5 Para uma maior e melhor discussão dessa relação entre grupos distintos é interessante observar o estudo de Elias no livro "Introdução à Sociologia", no item referente ao "Modelo de jogo de dois níveis: tipo oligárquico." (p. $93-96)$.

6 Esta referência liga-se ao trabalho de Doutorado de Patricia Silvestre de Freitas “As Múltiplas Educações: Esporte Adaptado!?” . Doutorado em Educação, Unimep, 2003. Um tratamento inicial, para debate com a autora citada durante o andamento da tese, pode ser encontrado em GEBARA, Ademir. Poder e Preconceito. In: Congresso Brasileiro de Atividade Motora Adaptada,4., out. 2001. Anais.... Curitiba, 2001, p. 34.
} 
casos em que o desequilíbrio de poder é maior ou menor, dependendo do estrato grupal e seu nível anômico. Aqui também temos que considerar a capacidade de infligir vergonha ao outro, ou melhor, de fazê-lo sentir vergonha de sua condição. E, como nos diria Goudsblom?, "ela (a vergonha) é derivada do medo; medo da perda dos dois mais preciosos reconhecimentos da vida social: o respeito e a afeição.” (2007, p.5). E completa, "Mais que qualquer outra emoção a vergonha é uma emoção exclusivamente social".

Da mesma maneira, é de se supor a existência de resistências, elas mesmas manifestação de poder de segmentos dos grupos outsiders, como se sabe, os cegos recusam seu pertencimento à identidade generalizadora.

4) Como os grupos estabelecidos compartilham uma história comum - memórias, eventualmente parentescos, favores, rixas e alegrias -, existe uma sólida articulação grupal. Desta maneira, os moradores da Aldeia acentuam o isolamento dos recém-chegados, com múltiplas origens e passado distinto. Eles são "gente diferente". Em qualquer caso, forasteiros colocam em risco os valores e a posição dos antigos moradores, por isso mesmo, a sociodinâmica dessas relações é sempre muito tensa.

5) Os grupos estabelecidos consideram-se sempre mais cultos, mais civilizados, mais decentes, mais respeitáveis, em suma, podemos afirmar que uma grande quantidade de conflitos sociais podem ser melhor compreendidos através da sociodinâmica das interdependências entre grupos estabelecidos e recém-chegados.

Duas questões merecem particular atenção ao tomarmos este modelo de análise como fonte inspiradora, para compreender os processos de constituição das identidades nacionais, especialmente em países colonizados, como no caso brasileiro. De um lado, a questão da colonização em si mesma, pois no dizer de Elias trata-se de um processo que deve ser visto a partir da sociodinâmica entre grupos comunitários e estados nacionais. $\mathrm{Na}$ medida em que as nações tornam-se socialmente mais diferenciadas, assumindo a maioria das funções anteriormente atribuídas às comunidades, evidencia-se um processo de desfuncionalização da vida comunitária - no caso do contato entre comunidades indígenas americanas e Estados Nacionais europeus em formação, este processo é evidente ${ }^{8}$.

Um dos mais radicais processos de informalização desse tipo foi a destruição dos rituais que davam significado à vida e sustentavam modelos de vida coletiva entre os povos mais simples, no processo de colonização e no trabalho missionário por europeus. Talvez fosse útil examinar isso brevemente. Um dos mais extremos exemplos da desvalorização de um código que fornece significado e orientação a um grupo em ligação com a perda de poder do seu grupo portador é a eliminação das

7 GOUDSBLOM, J. A vergonha: uma dor social. Trad. Ademir Gebara. Conferência de abertura do X Simpósio Processo Civilizador, realizado na UNICAMP em abril de 2007.

${ }^{8}$ ELIAS, Norbert (1997). Os Alemães: A luta pelo poder e a evolução dos habitus nos séculos XIX e XX. Zahar Editores, Rio de Janeiro, p. 77. 
classes superiores nas Américas Central e do Sul, no decorrer da colonização e imposição do cristianismo pelos espanhóis e portugueses.

De outro lado, a formação nacional brasileira, implicando aspectos até então não considerados de geopolítica, em que a posse de espaços geográficos 'vazios', de dimensões continentais, tem relevo significativo no processo de formação de fronteiras e limites. Fato este frequentemente de maior relevância do que a monopolização da violência e dos tributos. Além disso, um conjunto diferenciado de novas relações entre estabelecidos e recém-chegados, articulado a processos de desfuncionalização e informalização, mal permitem definir relações estáveis de poder. Índios, mestiços, portugueses, escravos africanos e imigrantes, em diferentes momentos, serão tipos humanos presentes nesse processo civilizacional, no qual um aparelho de governo centralizado desfuncionaliza permanentemente interdependências comunitárias.

Eis aí o porquê da questão higiênica crescentemente presente. A preocupação higienizante, neste caso, não é um problema de família, ou de uma 'classe' específica. Explicação mais comum nas interpretações em que a categoria "trabalho" centraliza a análise do desenvolvimento do sistema capitalista em sociedades específicas, esta é uma questão colocada já na carta de Caminha, reiterada pelos Jesuítas, recolocada na Reforma Pombalina, clara com a transferência da Corte Portuguesa e politizada em todo o século XIX.

Mas pensemos um pouco sobre o conhecimento como uma fonte de poder em potencial, como sugere Norbert Elias. Tanto quanto no passado, o poder militar foi garantido pela relação com a produção, bem como com a acumulação de armas e soldados; e hoje, o poder também se gesta na forma de conhecimento. Um novo tipo de conhecimento é também um novo lócus de poder. O poder potencial das massas está diretamente relacionado com o acesso a níveis mais elevados de educação. Como diria Elias, "o acesso a um conhecimento mais amplo, a maiores e mais compreensivos meios de orientação, incrementa o poder potencial dos grupos humanos.” (1994: 57). Olhando para um período passado, vemos o que significou para a Igreja Católica a emergência de um saber não centrado nos dogmas religiosos.

No sentido que vimos tratando até aqui o problema do poder é, certamente, um dos mais importantes no entendimento das sociedades, já que desempenha papel fundamental em todas as relações humanas. Elias frisa que, geralmente, para simplificarmos o problema, uma forma única, "talvez a forma militar ou a econômica, das muitas possíveis origens do poder acessíveis as pessoas, é muitas vezes tomada como a origem do poder da qual se decalcam todas as outras formas de exercício do poder" (Elias, 1994: 100). Isso porque, invariavelmente, não refletimos sobre a origem polimorfa desse elemento. 
Por fim, vale ressaltar que, para Elias, uma análise sociológica deve prestar atenção às mudanças que se produzem na distribuição de poder, fornecendo assim elementos mais palpáveis sobre as trocas nas estruturas sociais. Também os partidos políticos, nas sociedades mais diferenciadas de hoje, se configuram como umas das principais cadeias organizativas de que se servem diferentes grupos com o intuito de controlar e dirigir uns aos outros (Elias, 1994: 61). Porque, "o crescente poder potencial da população de um Estado está ligado a uma série de fatores como níveis de educação mais elevado, assim como uma maior dependência dos governos em respeito aos governados" (Elias, 1994: 97 - vide aí o crescente poder da chamada "opinião pública". Esses e outros elementos corroboram, nas palavras de Elias, o papel do conhecimento, pois, o próprio monopólio da violência física, um dos pilares da formação do Estado moderno, sua manutenção, depende hoje em parte do monopólio do conhecimento. Vejamos por certo, a corrida pelo pódio na codificação do DNA, ou das "guerras cirúrgicas" com a precisão de morte milimétrica, ou as mais refinadas ações de espionagem e controle. Afinal, é de um aspecto cada vez mais familiar aquele rostinho infantil, com um doce sorriso, que nos pede: "Sorria, você está sendo filmado!".

\section{Referências}

BERCITO, S. de D. R. (1991). Ser Forte para fazer a nação forte: a Educação Física no Brasil (1932 - 1945). Dissertação de Mestrado, FFLCH, Depto de História, USP

CASALECCHI, J. E. (1978). As Plataformas dos Candidatos à Presidência do Estado de São Paulo na Primeira República. In: EH 1 Boletim de Economia e História. Araraquara, Unesp.

ELIAS, N. (1974). Towards a theory of communities. In: C. Bell \& H. Newby (eds), The Sociology of Community, London, Frank Cass.

(1993). O processo Civilizador. Vol. 2. Rio de Janeiro: Jorge Zahar.

(1994). Conocimiento y poder. Madrid: La Piqueta.

(1994). A sociedade dos indivíduos. Rio de Janeiro: Jorge Zahar.

(1980). Introdução à sociologia. Braga: Edições 70.

(1997). Os Alemães: A luta pelo poder e a evolução dos habitus nos séculos XIX e XX. Rio de Janeiro, Zahar Editores. 
ELIAS, N. \& SCOTSON, J. L. (2000). Os Estabelecidos e os Outsiders: Sociologia das relações de poder a partir de uma pequena comunidade. (Vera Ribeiro, Trad.). Rio de Janeiro: Zahar Editor.

GEBARA, A. (2001). Poder e Preconceito. In: Congresso Brasileiro de Atividade Motora Adaptada, 4., out. 2001. Anais. Curitiba, p. 34.

(1998). A Pesquisa em História e Sociologia da Educação Física e do Esporte. In: Anais do II Simpósio Paulista de Educação Física, Rio Claro, SP, Instituto de Biociências, Depto de Educação Física, UNESP, p. 30-36.

GOUDSBLOM, J. (2007). A vergonha: uma dor social. Tradução de Ademir Gebara. Texto mimeografado.

VAN KRIEKEN, R. (1998). Norbert Elias. Coleção Key Sociogists. London, New York: Routledge.

SILVESTRE, P. F. (2003). As Múltiplas Educações: Esporte Adaptado! Doutorado em Educação, Unimep.

SOARES, C. L. (1994). Educação Física: Raízes Européias e Brasil. Campinas SP, Autores Associados. 